\title{
The effect of drug therapy on the uptake of radioactive fluorine by osseous metastases
}

\begin{abstract}
Radioisotopic techniques are potentially of considerable value to clinical pharmacology. Scintigrams and uptake studies are of particular interest, as they permit one to visualize lesions in many organs and to obtain simultaneously quantitative information on the degree of abnormality in the area of the lesion. Bone metastases take up increased amounts of fuorine-18; the present study was an investigation of the effect of therapy on this abnormal uptake. In eight patients with metastatic lesions to bone, chemotherapy or hormonal therapy produced temporary improvement in five, as judged by roentgenographic or clinical criteria, during the first four months after initiation of therapy. Serial scintigrams and quantitative uptake studies throughout this period showed that the abnormal ratio in fuorine uptake remained unchanged, despite the other evidence of temporary regression of metastases. Although the duration of time chosen for this study was consistent with that commonly used by physicians for evaluation of the effect of a given type of chemotherapy, our results suggest that such short-term studies must be interpreted cautiously.
\end{abstract}

\author{
Hermann G. Kampffmeyer, M.D.,* Howard Dworkin, M.D., \\ Edward A. Carr, Jr., M.D., and Frances E. Bull, M.D. Ann Arbor, Mich. \\ Departments of Pharmacology (Program in Investigational Clinical Pharmacology) \\ and Internal Medicine (Nuclear Medicine: Cancer Chemotherapy), University of Michigan
}

Labeled compounds are available to permit scintigrams of most organs of the body. These radioisotopic techniques must now be studied to determine their usefulness to clinical pharmacology. The present preliminary report will indicate some of the difficulties associated with such studies.

Roentgenography has already aided in the evaluation of certain forms of treatment, and the use of scintigrams may well lend increased objectivity to evaluation of

Supported by Training Grant 5TI-HE-5526-04, National Heart Institute.

Received for publication Nov. 30, 1966.

- Merck International Fellow in Clinical Pharmacology. therapy organs that cannot be well visualized by roentgenographic techniques. The use of radioisotopic techniques may even offer advantages for the study of organs in which standard roentgen films demonstrate lesions. The former permit scintigrams and determinations of uptake simultaneously, a quantification that is not provided by roentgenographic studies, and in certain instances also offer increased sensitivity. Unfortunately, some of the basic principles of clinical pharmacology, e.g., serial studies of the same patient before and during therapy with "blind" evaluation of the results, have been absent from most studies 
to date involving scintigrams. We have, therefore, attempted to apply these principles to scintigrams and uptake determinations obtained during the course of one type of therapy.

The specific purpose of the present short-term study was to obtain preliminary information about the effect, if any, of drug therapy on the uptake of radioactive fluorine by bony metastases. The study was carried out during a relatively short period (four months) after initiation of therapy, as we were particularly interested in exploring the possibility that serial studies of bone with radioactive fluorine might give the physician early evidence about the effectiveness or lack of effectiveness of any given drug chosen for the treatment of bony metastases. Bony metastases have been demonstrated to take up increased amounts of several radionuclides, including radioactive fluorine. Scintigrams are often positive before roentgenographic demonstration of such lesions is possible. ${ }^{8,11,19}$ This increased sensitivity of scintigrams and uptake studies, as compared to roentgen films, is not surprising. Although roentgenographic techniques are, of course, capable of diagnosing both osteoblastic and osteolytic lesions, experiments based on decalcification of whole bones have suggested that 20 to 50 per cent of the calcium must be removed before the loss of calcium is visible roentgenographically in the first place. ${ }^{1,17}$ The fact that scintigrams have often been shown to reveal metastases before x-ray films do suggests the possibility that changes in osseous metastases, caused by therapy, might also be detectable by radioisotopic techniques before other evidence of the change becomes available. The size of the lesion is also of importance, as lesions of 1 to 1.5 centimeters are usually the smallest that may be well visualized by $\mathrm{x}$-ray, ${ }^{2,4}$ but present scintigraphic techniques are not superior to roentgenographic techniques in this regard. With radioisotopic techniques the ratio of uptake by the lesion to uptake by surround- ing tissue is also, of course, a highly important factor.

\section{Methods}

Selection of radioisotope. Fluorine-18, introduced by Blau and Nagler, ${ }^{3}$ was selected because of its short physical halflife (110 minutes). The shorter physical half-life permits administration of a dose of $1 \mathrm{mc}$., with recording of a relatively high count rate shortly after administration of the radionuclide, while providing a relatively low radiation dose to the patient. ${ }^{10}$ The techniques used were the scintigram (bone scan) and the quantitative uptake study. ${ }^{10}$

Selection of subjects. Eight adult patients were selected with the diagnoses, confirmed histologically in every instance, of carcinoma of the breast in 6 , multiple myeloma in 1, and Hodgkin's disease in 1 . Each patient also met all of the following criteria: (a) evidence that the primary disease had already metastasized; a scintigram of at least one bone after administration of radioactive fluorine was positive at a time when the patient was receiving no chemotherapy or hormonal therapy for cancer; (b) no radiation therapy to the metastases under study had been given for at least 6 months prior to the beginning of the present study; (c) subsequent drug therapy was instituted within one week after the positive scintigram of bone had been obtained. In addition, 5 of the 8 patients had other evidence of bony metastases, i.e., roentgenographic, clinical, or both.

Technique of scintigrams and uptake studies. The preparation and use of fluorine-18 have previously been described. ${ }^{9}$ The radionuclide was produced in a carrier-free state in the Ford Nuclear Reactor of the University of Michigan by bombardment of enriched lithium- 6 carbonate with thermal neutrons. After rapid separation of the radioactive fluorine in the form of sodium fluoride," it was transported im-

\footnotetext{
* The cooperation of P. D. La Fleur is gratefully acknowledged.
} 
mediately to the University Medical Center and administered to the patients.

The dose of $1 \mathrm{mc}$. was administered intravenously in a volume of 5 to $10 \mathrm{ml}$. or orally in a volume of 25 to $50 \mathrm{ml}$. Approximately one hour after administration of the radioactive fluorine, the bony areas of interest and appropriate control areas were scanned with a photoscanner ${ }^{*}$ employing a 3 inch crystal and a 19 hole focusing collimator. In accordance with standard practice, normal adjacent and contralateral areas of bone were used as controls. Of the total of 94 scintigrams performed in this study, all but 3 were performed by the same individual. $\uparrow$ After completion of the scintigram the collimator was fixed in turn over each bony area of interest and appropriate control areas. The count rates obtained over these areas were recorded with the aid of a scaler attached to the scanner. For example, if the area of interest was the pelvis, a series of fifteen-second counts was usually taken from each of 15 different areas, which followed the anatomical landmarks of the pelvis in such a way as to map the entire pelvis.

Interpretation of scintigrams, evaluation of the patient's clinical findings, and interpretation of roentgen films were made at each visit by separate physicians, respectively. One of us arranged all appointments for patients, ordered the necessary studies, and collected all reports without discussing the results with our co-workers. Another (H. D.) received the radioisotopic data, including the scintigrams, directly from the technician and recorded his opinion in writing before he was informed of the results of other studies. Roentgen films, taken by standard techniques, were evaluated by a roentgenologist who had no knowledge of the other findings; in order to avoid introducing any characteristics of a "special study" into this evaluation, serial tomograms were not taken and only routine films were obtained serially. It is recog-

\footnotetext{
*Picker X-Ray Corporation, White Plains, N. Y.

fThe technical assistance of $\mathrm{Mr}$. Joseph Lessard is gratefully acknowledged.
}

nized that serial tomograms might have increased the frequency with which changes were detected roentgenographically. Clinical evaluation of each patient was carried out at the time of each visit by physicians who were not aware of the results of the radioisotopic studies or roentgenographic studies before they recorded their clinical impression in writing. Only after clinical, roentgenographic, and radioisotopic interpretations had been separately made and recorded, without reference one to the other, were all data collected and reviewed by the authors as a group. After recording his clinical impression, the physician supervising the patient's care had, of course, access to all data, but he did not discuss these with the various authors in any way that would vitiate the "blind" nature of the study.

After initial selections of patients, drug therapy was chosen by the physicians responsible for the clinical care of each patient, usually in the chemotherapy or breast cancer clinics. "In every instance the therapy chosen was that deemed best by the physician responsible for the patient's care and in no instance did the present study play any role in the decision to select a particular agent. Analgesics were given whenever indicated throughout the course of the study.

In addition to the scintigram made within one week prior to the beginning of drug therapy, each patient was again scanned at intervals after initiation of therapy. The usual intervals were 1,2 , and 4 weeks after initiation of therapy. Seven of 8 patients were also scanned at 8 weeks after the beginning of therapy, 6 at 12 weeks, 5 at 16 weeks, 5 at 24 weeks, and 1 at 30 weeks. In addition to the scintigram and uptake determinations, clinical evaluation, and roentgen studies that were made at each visit, determinations of serum calcium, phosphorus, and alkaline phosphatase were regularly performed in the

\footnotetext{
* We are grateful to Drs. A. Burgess Vial and Courtland M. Schmidt for their contribution to the care of these patients.
} 
central biochemical laboratory of the hospital.

\section{Results}

Five patients had clinical, roentgenographic, or combined evidence of improvement during the course of therapy (Table I). In no instance was a clear change in the scintigram observed.

$A$

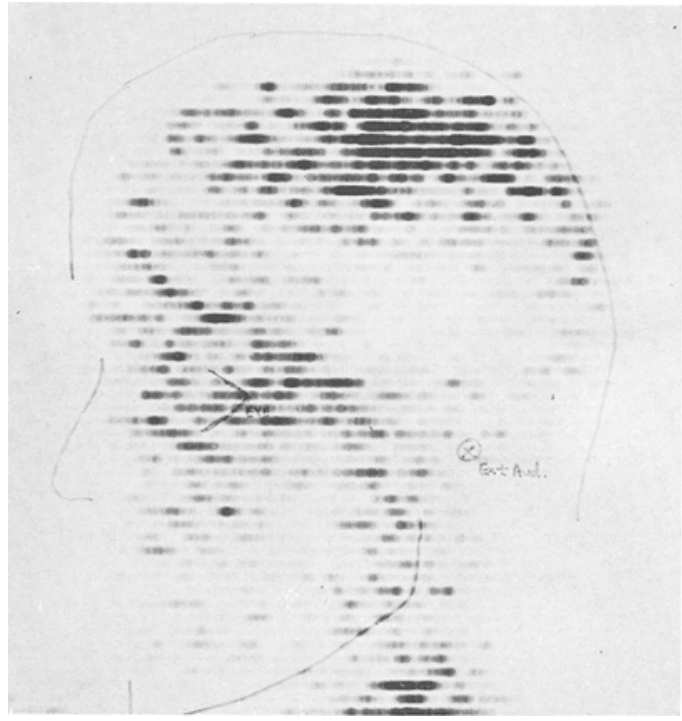

C

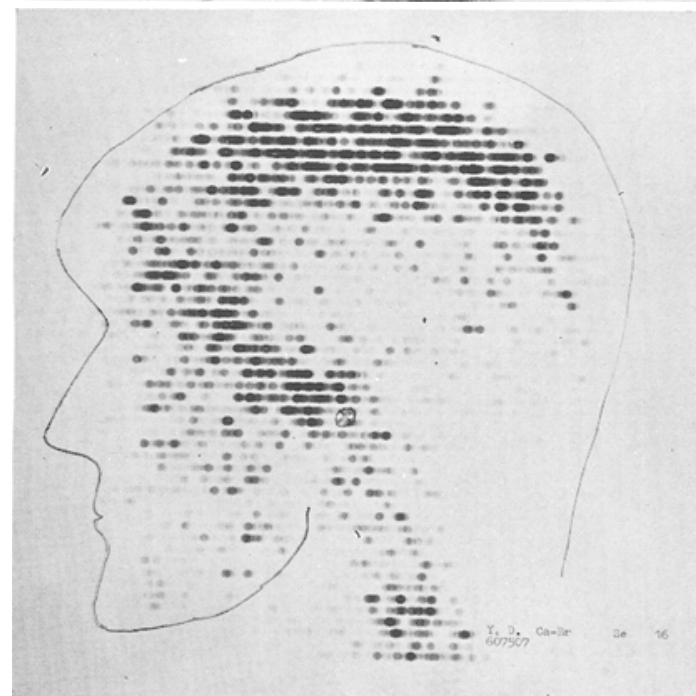

Figs. 1 and 2 exemplify the results obtained in the entire series of patients. In the set of scintigrams shown in Fig. 1, there is no significant change in the "hot" area of increased uptake, relative to the uptake in surrounding normal areas. It should be stressed that the degree of abnormality of a scintigram after administration of radioactive fluorine must be judged

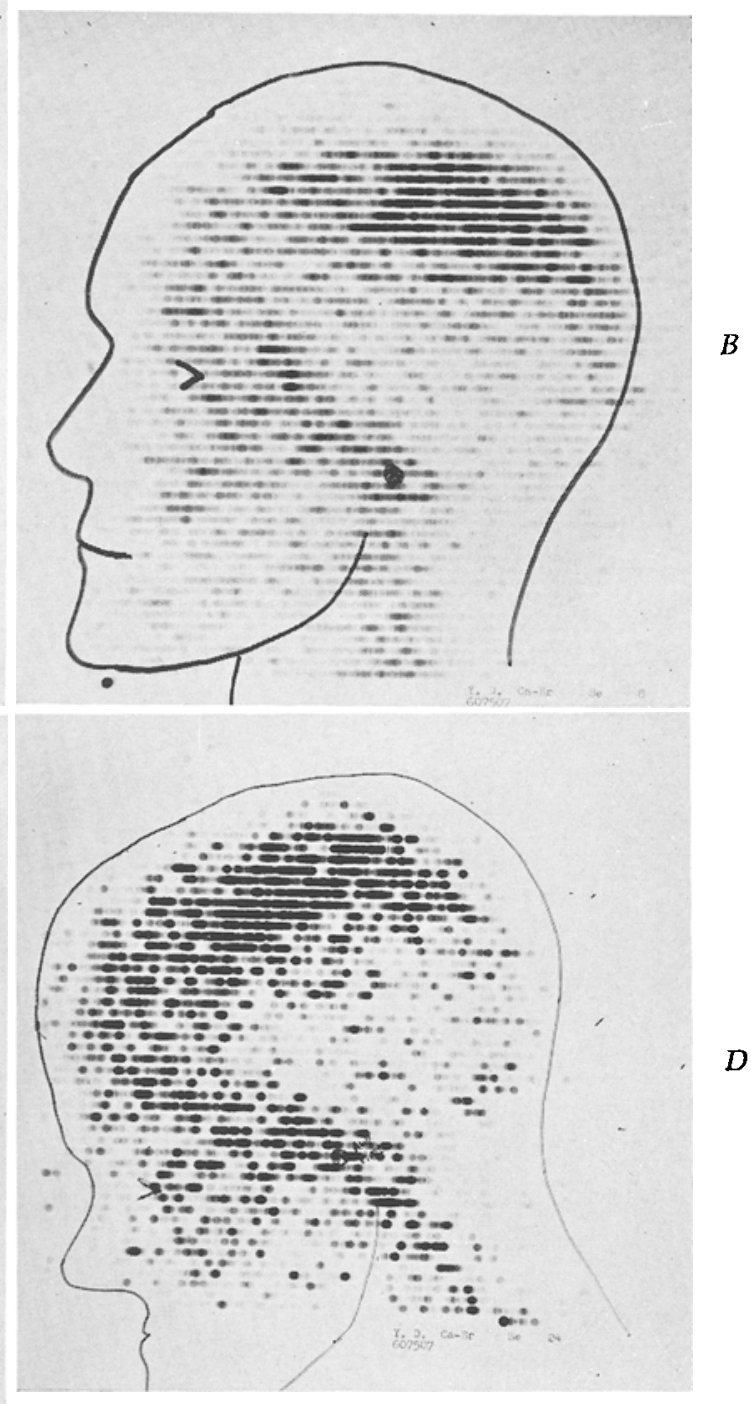

Fig. I. Scintigrams of the skull of Patient Y. D.: $A$, before treatment; $B$, 8 weeks after beginning of treatment; $C, 16$ weeks after beginning of treatment; and $D, 24$ weeks after beginning of treatment. In comparing the "hot" area in the parietal bone with the frontal bone, no significant changes in relative uptake are observable, despite over-all changes in the density of the scintigram. Scintigrams taken at $1,2,4$, and 12 weeks in this patient were also similar to those shown. 
with reference to the background counts obtained over normal areas. This criterion is much more reliable than the absolute density, for the latter may vary considerably from one scintigram to another on the basis of technical scanning factors. In Fig. 2, questionable changes in the scintigrams were observed during the course of therapy. Changes of this degree were observed in 7 of the 8 patients. The lack of a clear trend toward either an increase or decrease throughout the course of therapy in any patient and the lack of confirmatory changes in the uptake measurements ob- tained by point counting (see below) argue against the significance of these changes in the scintigram.

The changes in uptake values, as obtained by serial point counting, are summarized in Table II. Therapy produced no significant trend toward increase or decrease in the ratio, counts per minute over lesion/counts per minute over control area. Here again, the absolute counts per minute obtained by point counting varied considerably from week to week, but the ratio, counts per minute over lesion/counts per minute over control area, was less variable.
A
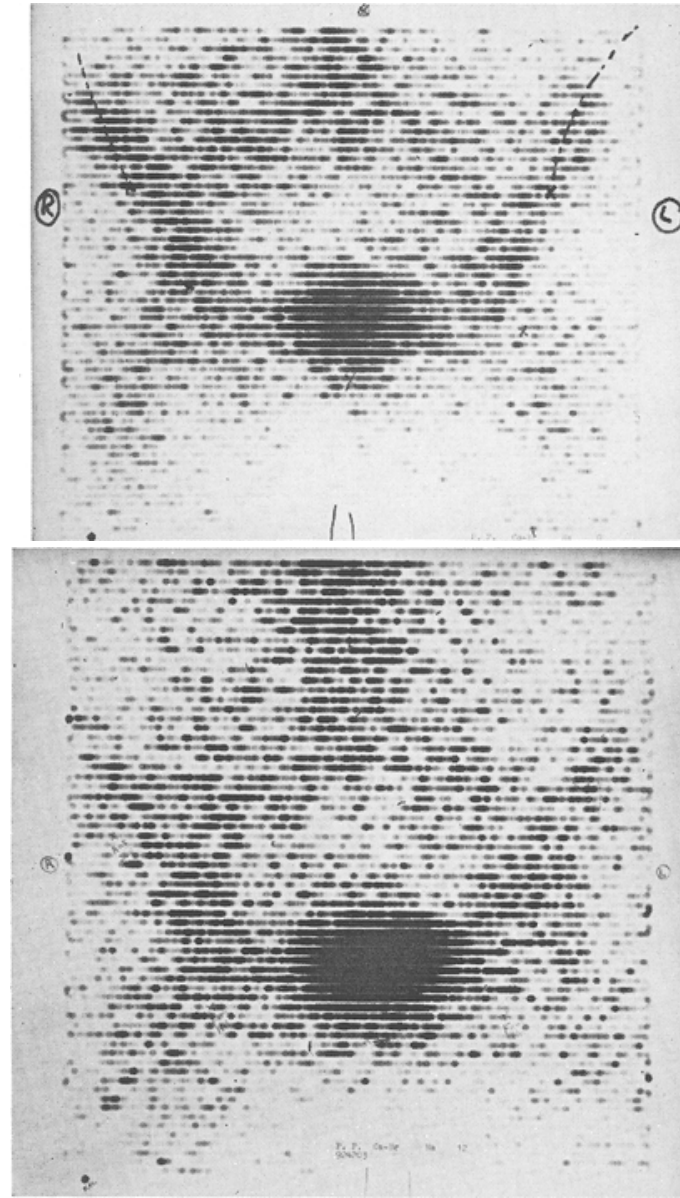

(C)

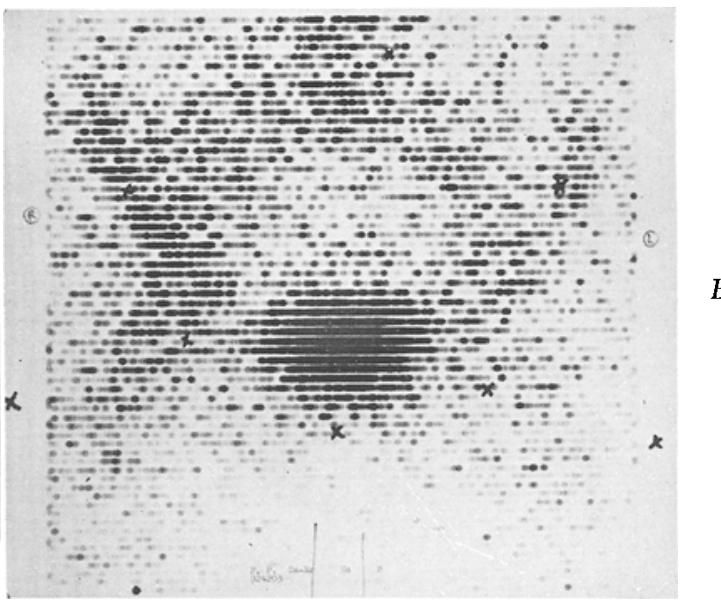

$B$

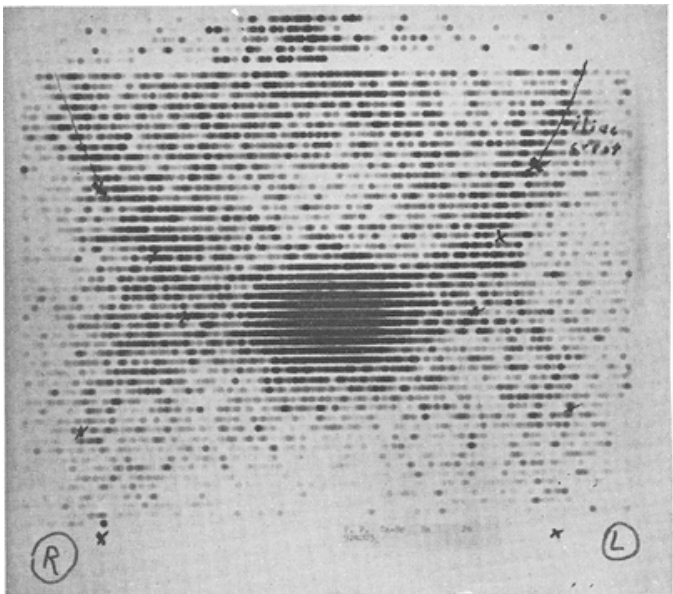

Fig. 2. Scintigrams of the pelvis of Patient P. P.: $A$, before treatment; $B, 8$ weeks after beginning of treatment; $C, 12$ weeks after beginning of treatment; and $D, 24$ weeks after beginning of treatment. All four scintigrams show a high uptake on the right side of the pelvis. There is no discernible trend during therapy, as the difference between sides is greatest in $B$ and least in $C$. Scintigrams taken at $1,2,4$, and 16 weeks in this patient were not significantly different from those shown here. 
Table I. Characteristics of patients studied

\begin{tabular}{l|c|c|l|c|c|c}
\hline & & & & \multicolumn{3}{|c}{ Evidence of osseous metastases } \\
\cline { 4 - 7 } Patient & Age & Sex & \multicolumn{1}{c}{ Diagnosis } & Scan & X-ray & Clinical \\
\hline B. M. & 54 & F & Carcinoma of breast & Yes & No & Yes \\
& & & & & & \\
R. J. & 52 & F & Carcinoma of breast & Yes & No & Yes \\
Y. D. & 66 & F & Carcinoma of breast & Yes & Yes & No \\
P. P. & 44 & F & Carcinoma of breast & Yes & No & No \\
H. L. & 73 & F & Carcinoma of breast & Yes & Yes & No \\
J. M. & 67 & F & Carcinoma of breast & Yes & Yes & Yes \\
G. E. & 74 & F & Multiple myeloma & Yes & Yes & Yes \\
H. E. & 33 & M & Hodgkin's disease & Yes & No & No \\
\hline
\end{tabular}

*This patient had metastases in spine and pelvis. Scan, $x$-ray, and clinical findings were all positive for each site. After treatment was then discontinued and drug therapy was reinstituted. Subsequent clinical and roentgenographic evidence of

Table II. Uptake of radioactive fuorine by bony lesions (L) and control areas (C) as measured

\begin{tabular}{|c|c|c|c|c|c|c|c|c|c|}
\hline \multirow[b]{2}{*}{$\begin{array}{l}\text { Week of } \\
\text { treatment }\end{array}$} & \multicolumn{6}{|c|}{ Patient B. $M$. } & \multicolumn{3}{|c|}{ Patient $R . J$. } \\
\hline & $\begin{array}{c}L \\
R S I\end{array}$ & $\begin{array}{c}C \\
L S I\end{array}$ & $L / C$ & $\begin{array}{c}L \\
6 t h T V\end{array}$ & $\begin{array}{c}C \\
2 n d L V\end{array}$ & $L / C$ & $\begin{array}{c}L \\
5 t h T V\end{array}$ & $\begin{array}{c}C \\
7 t h T V\end{array}$ & $L / C$ \\
\hline 0 & 1,500 & 1,400 & 1.07 & 3,500 & 2,700 & 1.30 & 2,200 & 1,800 & 1.22 \\
\hline 1 & 一 & - & - & - & - & - & 2,500 & 2,300 & 1.09 \\
\hline 2 & 2,776 & 2,448 & 1.13 & 6,828 & 4,844 & 1.41 & 1,304 & 1,276 & 1.02 \\
\hline 4 & 1,492 & 944 & 1.57 & 4,140 & 2,900 & 1.43 & $1,664^{*}$ & $1,364^{*}$ & $1.22^{*}$ \\
\hline 8 & 4,728 & 3,204 & 1.48 & 4,100 & 3,444 & 1.19 & 2,136 & 1,740 & 1.23 \\
\hline 12 & 2,500 & 1,884 & 1.33 & 2,412 & 1,644 & 1.47 & 3,220 & 2,924 & 1.10 \\
\hline 16 & 2,796 & 2,192 & 1.27 & 3,468 & 2,364 & 1.54 & 一 & $\longrightarrow$ & - \\
\hline 24 & 2,920 & 2,716 & 1.08 & 4,512 & 2,972 & 1.52 & 一 & $\longrightarrow$ & - \\
\hline 30 & - & 一 & 一 & - & - & 一 & 一 & $\longrightarrow$ & - \\
\hline $\mathrm{Abl}$ & & $\begin{array}{l}\text { acic } \\
\text { har }\end{array}$ & rio & $\begin{array}{l}\text { of ilium } \\
\text { illium }\end{array}$ & $\begin{array}{l}\text { RPAR. } \\
\text { LPAR, } \\
\text { FR, }\end{array}$ & $\begin{array}{l}\text { rietal } \\
\text { etal } \\
\text { one. }\end{array}$ & & & \\
\hline
\end{tabular}

"Studied at 6 weeks instead of 4 weeks.

† Area irradiated during these weeks.

Table II. Cont'd

\begin{tabular}{|c|c|c|c|c|c|c|c|c|c|}
\hline \multirow[b]{2}{*}{$\begin{array}{l}\text { Week of } \\
\text { treatment }\end{array}$} & \multicolumn{3}{|c|}{ Patient $H . L$. } & \multicolumn{6}{|c|}{ Patient $J . M}$. \\
\hline & $\begin{array}{c}L \\
R S I\end{array}$ & $\begin{array}{c}C \\
L S I \\
\end{array}$ & $L / C$ & $\begin{array}{c}L \\
L S I\end{array}$ & $\begin{array}{c}C \\
R S I\end{array}$ & $L / C$ & $\begin{array}{c}L \\
2 n d L V\end{array}$ & $\begin{array}{c}C \\
\text { Sacrum }\end{array}$ & $L / C$ \\
\hline 0 & 1,052 & 828 & 1.27 & 2,400 & 1,976 & 1.22 & 4,580 & 3,808 & 1.20 \\
\hline 1 & 1,748 & 1,488 & 1.18 & 2,264 & 3,064 & 0.74 & 6,168 & 5,428 & 1.14 \\
\hline 2 & 844 & 1,108 & 0.76 & 2,552 & 2,768 & 0.92 & $6,016 \uparrow$ & 5,680 & 1.06 \\
\hline 4 & 2,032 & 1,612 & 1.26 & 2,192 & 1,860 & 1.18 & $7,004 \nmid$ & 6,476 & 1.09 \\
\hline 8 & 1,048 & 1,148 & 0.92 & 1,340 & 1,116 & 1.20 & 3,492 & 2,960 & 1.18 \\
\hline 12 & 1,708 & 1,780 & 0.96 & 1,268 & 1,068 & 1.19 & 2,884 & 2,312 & 1.25 \\
\hline 16 & 1,896 & 1,808 & 1.05 & 1,180 & 988 & 1.20 & 2,832 & 2,108 & 1.34 \\
\hline 24 & 1,392 & 1,224 & 1.14 & 1,724 & 1,040 & 1.66 & 4,592 & 3,816 & 1.20 \\
\hline 30 & - & - & - & 1,350 & 1,300 & 0.98 & 4,100 & 3,500 & 1.17 \\
\hline & $\mathbf{L}$ & bar & & $\begin{array}{l}\text { ilium } \\
\text { itum }\end{array}$ & $\begin{array}{c}\text { RPAR, } \\
\text { LPAR, } \\
\text { FR, }\end{array}$ & etal & & & \\
\hline
\end{tabular}

* Studied at 6 weeks instead of 4 weeks.

fArea irradiated during these weeks. 


\begin{tabular}{l|c|c|c|c}
\hline \multicolumn{1}{c}{ Therapy } & $\begin{array}{c}\text { Duration of } \\
\text { study (weeks) }\end{array}$ & Scan & \multicolumn{2}{c}{ Significant posttreatment changes } \\
\hline Cyclophosphamide & 24 & None & None & Clinical findings \\
Cyclophosphamide & 12 & None & None & $\begin{array}{l}\text { Improvement at } 6 \text { weeks } \\
\text { Relapse at } 24 \text { weeks }\end{array}$ \\
Diethylstilbestrol & 24 & None & Improvement at 24 weeks & None \\
Fluoxymesterone & 24 & None & None & None \\
Diethylstilbestrol & 24 & None & None & Improvement at 2 weeks \\
Cyclophosphamide & 30 & None & Improvement at 24 weeks & Improvement at 12 weeks \\
Cyclophosphamide & 8 & None & None & Improvement at 8 weeks \\
Nitrogen mustard & 4 & None & None & None \\
\hline
\end{tabular}

completion of one week of drug treatment this was omitted for 4 weeks while $x$-ray treatment was given to the spine. $X$-ray improvement was noted in both spinal and pelvic lesions.

by point counting (all values except ratios refer to counts per minute)

\begin{tabular}{|c|c|c|c|c|c|c|c|c|}
\hline \multicolumn{6}{|c|}{ Patient $Y, D}$. & \multicolumn{3}{|c|}{ Patient $P . P$. } \\
\hline $\begin{array}{c}L \\
R S I\end{array}$ & $\begin{array}{c}C \\
L S I\end{array}$ & $L / C$ & $\begin{array}{c}L \\
L P A R\end{array}$ & $\begin{array}{c}C \\
F R \\
\end{array}$ & $L / C$ & $\begin{array}{c}L \\
R S I\end{array}$ & $\begin{array}{c}C \\
L S I \\
\end{array}$ & $L / C$ \\
\hline 2,944 & 2,388 & 1.23 & 2,872 & 1,360 & 2.11 & 1,336 & 1,168 & 1.14 \\
\hline 2,064 & 1,712 & 1.21 & 3,484 & 1,872 & 1.86 & 1,768 & 1,560 & 1.13 \\
\hline 3,004 & 2,200 & 1.37 & 2,748 & 1,848 & 1.49 & 1,684 & 1,372 & 1.22 \\
\hline 3,272 & 2,580 & 1.27 & 2,144 & 1,240 & 1.73 & 1,364 & 1,264 & 1.08 \\
\hline 3,776 & 2,840 & 1.33 & 3,156 & 2,104 & 1.50 & 2,064 & 1,544 & 1.34 \\
\hline 2,616 & 1.952 & 1.34 & 2,264 & 1,320 & 1.72 & 1,404 & 1,456 & 0.97 \\
\hline 2,524 & 2,260 & 1.12 & 1,904 & 1,140 & 1.67 & 872 & 620 & 1.41 \\
\hline 2,284 & 2,040 & 1.12 & 2,136 & 1,276 & 1.67 & 1,598 & 1,536 & 1.04 \\
\hline- & 一 & - & - & - & -- & - & - & - \\
\hline
\end{tabular}

\begin{tabular}{|c|c|c|c|c|c|c|c|c|}
\hline \multicolumn{6}{|c|}{ Patient G. E. } & \multicolumn{3}{|c|}{ Patient $H, E$. } \\
\hline $\begin{array}{c}L \\
R S I\end{array}$ & $\begin{array}{c}C \\
L S I\end{array}$ & $L / C$ & $\begin{array}{c}L \\
F R\end{array}$ & $\begin{array}{c}C \\
R P A R\end{array}$ & $L / C$ & $\stackrel{L}{L t h T V}$ & $\begin{array}{c}C \\
3 r d L V\end{array}$ & $L / C$ \\
\hline 1,456 & 1,724 & 0.84 & 1,788 & 1,336 & 1.34 & 4,200 & 3,400 & 1.24 \\
\hline 2,928 & 2,512 & 1.17 & 2,172 & 1,348 & 1.61 & 3,000 & 2,864 & 1.05 \\
\hline - & - & - & - & 一 & - & 2,840 & 2,532 & 1.12 \\
\hline 2,808 & 2,524 & 1.11 & 1,988 & 1,288 & 1.54 & 3,136 & 2,680 & 1.17 \\
\hline 940 & 752 & 1.25 & 616 & 572 & 1.09 & - & - & -- \\
\hline 一 & - & 一 & - & - & - & - & - & - \\
\hline - & 一 & 一 & - & - & - & 一 & 一 & - \\
\hline - & 一 & 一 & - & - & - & - & 一 & 一 \\
\hline- & - & - & - & 一 & - & - & - & - \\
\hline
\end{tabular}


Table III shows the serial values of serum calcium, phosphorus, and alkaline phosphatase concentrations in these patients. No significant trend was apparent during the course of therapy except for changes in serum phosphorus concentration. The latter fell in four patients (Y. D., P. P., H. L., and G. E.) but the presence or absence of this fall did not correlate significantly with the presence or absence of improvement of the patient.

\section{Discussion}

The primary purpose of this study was to apply the techniques of nuclear medicine to clinical pharmacology. Although certain tentative conclusions may be drawn from the present study, a realistic evaluation of the difficulties encountered is also neces- sary. Moreover, among the variety of labeled compounds that have been developed to permit scintigraphic demonstration of lesions in different organs, the mechanisms of uptake differ greatly. Therefore, the short-term and long-term effects of drug therapy on scintigrams and uptake values will require separate investigation for each organ to determine the proper place of radioisotopic studies in clinical pharmacology.

In the specific model we chose, uptake studies by point counting were of considerable help in supplementing the scintigrams, especially in the original classification of scans as positive or negative. The primary criterion of positivity of a scan was increased density over one or more areas as compared to background. This

Table III. Serial values of serum calcium, phosphorus, and alkaline phosphatase

\begin{tabular}{|c|c|c|c|c|c|c|c|c|c|}
\hline \multirow[b]{2}{*}{ Patient } & \multicolumn{9}{|c|}{ Week of treatment } \\
\hline & 0 & 1 & 2 & 4 & 8 & 12 & 16 & 24 & 30 \\
\hline \multicolumn{10}{|c|}{$\overline{\text { Calcium (mg. \%) }}$} \\
\hline B. $\mathrm{M}$. & 10.8 & 12.0 & 11.2 & 11.3 & 9.1 & 12.0 & 11.7 & 11.3 & - \\
\hline R. J. & 9.3 & 9.4 & 9.3 & $9.8^{*}$ & 8.8 & 10.2 & - & - & - \\
\hline Y. D. & 9.9 & 10.1 & 8.5 & 9.7 & 9.1 & 10.3 & 9.5 & 9.7 & - \\
\hline P. P. & 10.0 & - & 9.6 & 10.3 & 10.6 & 9.9 & 9.4 & 10.0 & - \\
\hline H. L. & 10.1 & 9.6 & 8.2 & 10.1 & 10.7 & 9.4 & 9.6 & 9.4 & - \\
\hline J. M. & 10.3 & - & 10.0 & 10.1 & 10.4 & 9.9 & 10.3 & 9.8 & 10.2 \\
\hline G. E. & 10.6 & - & 9.9 & - & 8.2 & - & - & - & - \\
\hline H. E. & - & 9.6 & 9.2 & 9.4 & - & - & - & - & - \\
\hline \multicolumn{10}{|c|}{ Phosphorus (mg. \%) } \\
\hline B. $\mathrm{M}$. & 2.8 & 3.3 & 3.4 & 3.2 & 2.7 & 3.1 & 3.5 & 3.0 & - \\
\hline R. J. & 4.7 & 4.8 & 3.6 & $4.4^{*}$ & 4.5 & 4.5 & - & - & - \\
\hline Y. D. & 3.8 & 2.7 & 2.8 & 2.7 & 2.7 & 2.9 & 2.3 & 2.7 & - \\
\hline P. P. & 4.4 & 3.3 & 4.2 & 4.2 & 3.6 & 2.8 & 3.0 & 3.2 & - \\
\hline H. L. & 4.0 & 3.8 & 3.0 & 3.4 & 2.2 & 2.3 & 2.2 & 2.3 & - \\
\hline J. M. & 3.5 & - & 3.7 & 4.2 & 3.3 & 3.6 & 3.8 & 3.3 & 3.7 \\
\hline G. E. & 4.7 & - & 2.9 & - & 2.5 & - & - & - & - \\
\hline H. E. & - & 4.2 & 3.3 & 4.7 & - & - & - & - & - \\
\hline \multicolumn{10}{|c|}{ Alkaline phosphatase (King-Armstrong units) } \\
\hline B. $\mathrm{M}$. & 80.0 & 76.0 & 79.0 & 55.0 & - & 22.0 & 22.0 & 60.0 & - \\
\hline R. J. & 6.5 & 8.4 & 7.8 & $8.1^{*}$ & 9.3 & 8.6 & - & - & - \\
\hline Y. D. & 7.8 & 9.6 & 9.2 & 8.8 & 9.1 & 10.1 & 8.3 & 10.7 & - \\
\hline P. P. & 9.7 & 6.3 & 8.1 & 8.5 & 8.1 & 5.1 & 7.6 & 7.4 & - \\
\hline H. L. & 14.0 & 16.0 & 9,5 & 11.8 & 11.3 & 14.9 & 12.0 & 11.0 & - \\
\hline J. M. & 41.0 & - & 25.0 & 23.7 & 22.0 & 24.0 & 23.0 & 24.3 & 25.0 \\
\hline G. E. & 6.4 & 一 & 7.6 & - & 9.4 & $\ldots$ & - & - & - \\
\hline H. E. & 15.0 & 20.8 & 12.3 & 13.0 & - & $\ldots$ & - & - & - \\
\hline
\end{tabular}

"Studied at 6 weeks instead of 4 . 
was confirmed, in every instance but one, by point counts that showed the suspected lesion to have at least 20 per cent more activity than the control area. However, point counting presents technical difficulties in accurate localization of the probe over the various areas of interest, particularly when the counting is done on a routine basis. Therefore, we are justified in concluding only that our present techniques suggested the absence of any large change in scintigrams or uptake values during a period when 5 of the 8 patients studied showed other evidence consistent with improvement under therapy.

Although a recognized difficulty in evaluating the significance of the present radioisotopic study is the fact that the other methods of evaluating improvement under therapy may themselves have been misleading, the possibility that the improvement noted may have been completely illusory seems remote. In patients Y. D. and J. M. improvement in bony metastases was eventually shown roentgenographically. The clinical improvement in patients B. M. and G. E. was also sufficiently definite to suggest favorable effect of therapy on bony metastases. $\mathrm{Pa}$ tient B. M. had metastases, demonstrated by scintigram, in the spine and pelvis, while patient G. E. had definite roentgenographic and scintigraphic evidence of widespread lesions of multiple myeloma in the pelvis and skull. Both B. M. and G. E. had difficulty in walking; B. M. had back pain while G. E. had diffuse bone pain. Following therapy, B. M. reported a remarkable decrease in back pain, G. E. noted disappearance of her bone pain, and both had improvement in their ability to walk. In addition, a striking decrease in the hepatomegaly of B. M. was observed.

At present it is uncertain whether the increased deposition of radioactive fluorine around bony lesions is primarily related to increased local blood flow accompanying these lesions, increased availability of denuded surface of bone for exchange, or some other factor. It would, therefore, be difficult to predict a priori what changes one might expect if therapy caused "healing" of metastases, i.e., one might expect the fluorine uptake to increase or decrease during such "healing." But in any event, significant changes in fluorine uptake were not observed under the conditions of this study.

Reported experience with the uptake of other radionuclides by bony metastases and the changes induced by therapy should be noted. Several investigators ${ }^{14,16,20}$ have described changes in the uptake of strontium- 85 by bony metastases after therapy, as determined by point counting or scanning. Both increased and decreased uptake have been claimed as a result of therapy. None of these reports described more than 3 patients. Moreover, none of the patients reported can be compared strictly with those studied in the present series, for the patients reported by the aforementioned authors differed from our patients in one or more of the following respects: no mention was made of "blind" evaluations, conclusions were based primarily on changes in lesions for which x-ray therapy or surgery (castration) was also used, or the patients were scanned only at intervals of 5 to 6 months or longer. Several authors $^{5,7,1 i n, 18}$ have reported changes in uptake of calcium- 47 after therapy of bony metastases, as determined by point counting or scanning. Here again, both increased and decreased uptake after therapy have been claimed and evaluations were apparently not "blind." Reports usually concerned 1 to 3 patients. Most of the patients were not comparable to ours in that surgical removal of endocrine organs or x-ray therapy played a major role in the treatment of the former. Moreover, in certain instances evaluation was based on comparison of a treated lesion and an untreated lesion, rather than serial studies of the same lesion before and after treatment. But Corey ${ }^{7}$ did report serial studies of retention of strontium-85 by a patient with two vertebral metastases from breast carcinoma. Initially both sites showed high 
uptake of strontium. Seventy-five days after the beginning of testosterone therapy the retention of strontium by one metastatic site had fallen to the same level as in the normal spine, while the other site continued to show high retention. In summary, studies with radioactive calcium and strontium, as reported thus far, do not clearly show that these radionuclides would behave differently from radioactive fluorine in a controlled study of the short-term effect of drug therapy on bony metastases, although the restrictions on measurement imposed by the short physical half-life of fluorine-18 and the difference between the kinetics of fluorine-18 and the kinetics of calcium and strontium make it unwise to compare fluorine studies closely with calcium-strontium studies.

Extension of our conclusions to radiation therapy does not seem justified. Significant reversal of a positive bone scan in a patient with reticulum cell sarcoma has been reported during a 3 months' period of observation after radiation therapy. ${ }^{11}$ Greenberg and co-workers ${ }^{13}$ have reported a difference between an untreated lesion of reticulum cell sarcoma and a radiationtreated lesion when both were studied serially in the same patient with calcium47. Finston, Woodard, and Laughlin ${ }^{12}$ have shown in dogs that irradiation affects the retention of calcium- 47 and strontium- 85 even in bone that was normal before irradiation.

Our results thus far suggest that radioisotopic studies of bone will continue to show definite abnormalities at the site of metastases, even when current forms of drug therapy have produced temporary improvement, as judged by other criteria. However, the short-term nature of the study and the preliminary nature of the conclusions drawn from it should be stressed. As noted above, the other criteria of temporary improvement are not always reliable indicators of the true state of bony lesions, and our present conclusions may reflect more the difficulties in interpretation posed by current fluorine uptake tech- niques than a true lack of correlation between the effect of therapy and the turnover of the radionuclide in bone. Nevertheless, our results thus far suggest that the effects of cancer chemotherapeutic agents should probably not be determined on a short-term basis and that some of the commonly accepted short-term criteria for judging the success of cancer chemotherapy may be misleading.

\section{References}

1. Babaiantz, L.: Les osteoporoses, Radiol. Clin. 16:291-322, 1947 .

2. Bachmann, A. L., and Sproul, E. E.: Correlation of radiographic and autopsy findings in suspected metastases in the spine, Bull. New York Acad. Med. 31:146-148, 1955.

3. Blau, M., and Nagler, W.: Fluorine-18: A new isotope for bone scanning, J. Nucl. Med. 3:332-334, 1962.

4. Borak, J.: Relationship between the clinical and roentgenological findings in bone metastases, Surg. Gynec. \& Obst. 75:599-604, 1942.

5. Brady, L. W., Croll, M. N., Stanton, L., Hyman, D., and Robins, S.: Evaluation of calcium-47 in normal man and its use in the evaluation of healing following radiation therapy in metastatic disease, Radiology 78:286$288,1962$.

6. Corey, K. R., Kenney, P., and Greenberg, E.: The use of calcium-47 in diagnostic studies of patients with bone lesions, Am. J. Roentgenol. 85:955-975, 1961.

7. Corey, K. R.: The turnover of $\mathrm{Ca}-47$ and Sr85 in bone lesions, in Medical uses of calcium47, Internat. Atomic Energy Agency, Tech. Rep. Series 32:148-152, 1964.

8. DeNardo, G. L.: The ${ }^{85} \mathrm{Sr}$ scintiscan in bone disease, Ann. Int. Med. 65:44-53, 1966.

9. Dworkin, H. J., and La Fleur, P. D.: Fluorine18: Production by neutron activation and pharmacology, in Radioactive pharmaceuticals, Division of Technical Information, U.S.A.E.C., 1966, pp. 635-648.

10. Dworkin, H. J., Moon, N. F., Lessard, R. J., and La Fleur, P.: A study of the metabolism of fluorine-18 in dogs and its suitability for bone scanning, J. Nucl. Med. 7:510-520, 1966.

11. Dworkin, H. J., and Filmanowicz, E. V.: Radiofluorine bone photoscanning of reticulum cell sarcoma, J. A. M. A. 198:985-988, 1966.

12. Finston, R. A., Woodard, H. Q., and Laughlin, J. S.: Effects of external irradiation on mineral metabolism in the bones of adult dogs, Clin. Orthop. 46:183-201, 1966.

13. Greenberg, E. J., Rorthschild, E. O., De Palo, 
A., and Laughlin, J. S.: Bone scanning for metastatic cancer with radioactive isotopes, Med. Clin. North America 50:701-710, 1966.

14. Gynning, J., Langeland, P., Lindberg, S., and Waldeskog, B.: Localization with $\mathrm{Sr}-85$ of spinal metastases in mammary cancer and changes in uptake after hormone and roentgen therapy, a preliminary report, Acta Radiol. 55:119-128, 1961 .

15. Jasinaki, W. K., Tolwinski, J., Malinowski, Z., Malkolska, J., and Gwiadowska, B.: Localization of Ca-47 in bone tumor, in Medical uses of calcium-47, Internat, Atomic Energy Agency, Tech. Rep. Series 10:102-194, 1962.

16. Kofman, S., Sky-Peck, H. H., Thibeaudeau, Y., Ray, R. D., and Taylor, S. G.: The use of strontium-85 in the evaluation of bone metastases, a preliminary report, J. Nucl. Med. 4: 9-17, 1963

17. Lachmann, E., and Whelan, M.: The roentgen diagnosis of osteoporosis and its limitations, Radiology 26:165-177, 1936.

18. Sargent, T., Linfoot, J. A., Stauffer, H., and Lawrence, J. H.: Use of a whole body counter in turnover studies with calcium-47, J. Nucl. Med. 5:407-416, 1964.

19. Sklaroff, D. M., and Charkes, N. D.: The detection of bone metastases by photoscanning with radioactive strontium, in Quinn, James L., editor: Scintillation scanning in clinical medicine, Philadelphia, 1964, W. B. Saunders Company, pp. 69-86.

20. Waldeskog, B., Gynning, J., and Langeland, P.: Localization with Sr-85 of spinal metastases in mammary cancer and changes in uptake after hormone and roentgen therapy, in Medical uses of calcium-47, Internat. Atomic Energy Agency, Tech. Rep. Series 10:104-106, 1962. 